
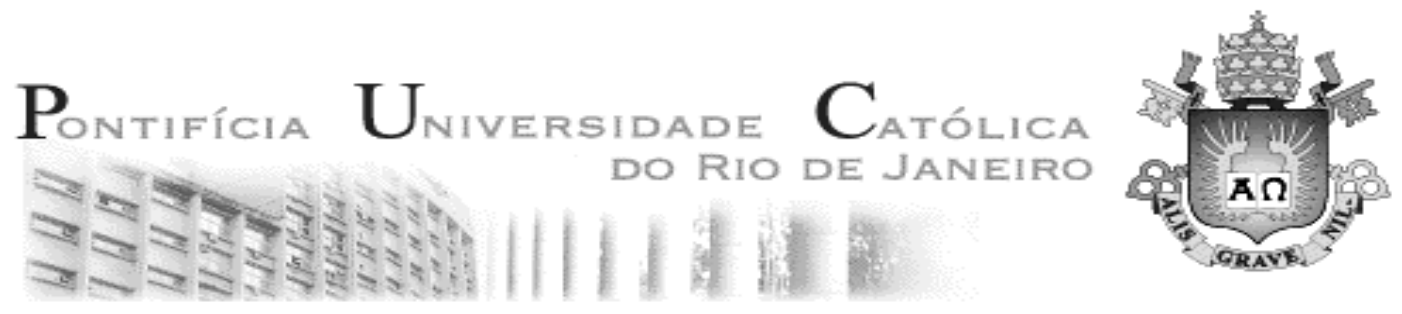

Anna Paula Lougon Duarte

Avaliação de Propriedades Termo-Hidráulicas de Solos Requeridas na Aplicação da Técnica de Dessorção Térmica

Tese de Doutorado

Tese apresentada ao Programa de Pós-graduação em Engenharia Civil da PUC-Rio como requisito parcial para a obtenção do título de Doutor em Engenharia Civil.

Área de Concentração: Geotecnia

Orientadores: Tácio Mauro Pereira de Campos José Tavares Araruna Júnior

Rio de Janeiro, 13 de fevereiro de 2004. 


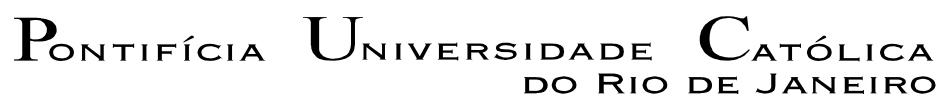

Anna Paula Lougon Duarte

\title{
Avaliação de Propriedades Termo-Hidráulicas de Solos Requeridas na Aplicação da Técnica de Dessorção Térmica
}

Tese apresentada como requisito parcial para obtenção do título de Doutor pelo Programa de Pós-Graduação em Engenharia Civil do Departamento de Engenharia Civil do Centro Técnico Científico da PUC-Rio. Aprovada pela Comissão Examinadora abaixo assinada.

\author{
Prof. Tácio Mauro P. de Campos \\ Presidente/Orientador \\ Departamento de Engenharia Civil - PUC-Rio \\ Prof. José T. Araruna Jr. \\ Co-Orientador \\ Departamento de Engenharia Civil - PUC-Rio \\ Prof. Manoel de Melo M. Nobre. \\ UFAL
}

Prof. Roberto F. de Azevedo UFV

Prof. Eurípedes do A. Vargas Jr. Departamento de Engenharia Civil - PUC-Rio

Prof. Franklin dos S. Antunes Departamento de Engenharia Civil - PUC-Rio

Prof. José Eugênio Leal Coordenador Setorial do Centro Técnico Científico - PUC-Rio

Rio de Janeiro, 13 de fevereiro de 2004. 
Todos os direitos reservados. É proibida a reprodução total ou parcial do trabalho sem autorização da universidade, da autora e do orientador.

\section{Anna Paula Lougon Duarte}

Engenheira Civil, formada pela UNB em 1995. Especialista em Geotecnia pela UnB em 1996. Especialista em Geotecnia pela Universidade de Brasília em 1996. Realizou o curso de extensão em Mecânica dos Solos e Engenharia de Fundações pelo CEDEX-Madrid em 1998. Concluiu o Mestrado em Engenharia Civil em 1999, com o estudo do mecanismo de ruptura da encosta em solo não saturado da Vista Chinesa. Atuante na área de Geotecnia Ambiental desde 1998.

Ficha Catalográfica

Duarte, Anna Paula Lougon.

Avaliação de Propriedades Termo-Hidráulicas de Solos Requeridas na Aplicação da Técnica de Dessorção Térmica / Anna Paula Lougon Duarte; orientadores: Tácio Mauro Pereira de Campos e José Tavares Araruna Júnior. - Rio de Janeiro: PUC, Departamento de Engenharia Civil, 2004.

v., [33], 290f. :il. ; 30cm

1.Tese (doutorado) - Pontifícia Universidade Católica do Rio de Janeiro, Departamento de Engenharia Civil.

Inclui referências Bibliográficas

1. Geotecnia ambiental. 2.Dessorção térmica. 3.Fluxo acoplado de calor e umidade em solos. 4.Efeitos de temperatura em solos. 5.Ensaios de laboratório 6.Solos nãosaturados. I.de Campos, Tácio M. P. (Tácio Mauro Pereira). II Pontifícia Universidade Católica do Rio de Janeiro. Departamento de Engenharia Civil. III. Título. 
Ao meu amado companheiro e grande amigo que me preenche a vida com tantas alegrias, meu marido Mário.

Aos meus PAIS, Edson e Anna, pelo apoio irrestrito, confiança incondicional e amor pleno. 


\section{Agradecimentos}

À Deus, por sua infinita bondade e amor, pois somente com sua benção foi possível a realização deste trabalho.

Aos Professores Tácio e Araruna pela valiosa orientação.

As instituições CAPES, PRONEX/CNPq e a PUC-Rio pelo apoio financeiro.

Aos professores do Departamento, pelos conhecimentos transmitidos e pela agradável convivência, em especial aos meus amigos Celso Romanel, Franklin Antunes e Vargas.

Um agradecimento todo especial a turma do laboratório, que com dedicação e competência foram imprescindíveis neste trabalho: "Mestre" William, "Seu" José, Amaury e Josué.

Aos funcionários do Departamento de Engenharia Civil pela disponibilidade, atenção e amizade, em especial a Ana Roxo, Fátima, Lenilson e Cristiano.

Ao professor Gusmão pela grande ajuda. Ao Victor Hugo pela participação na montagem dos equipamentos eletrônicos.

A Rosane Maia Nobre que muito colaborou dividindo os seus conhecimentos sobre fluxo de calor em solos.

Ao casal Ana Valéria e Luís Bertolino pela presteza e simpatia, na ajuda com o microscópio eletrônico. 
Aos meus pais incentivadores, os quais são meu palco e minha platéia, dizer obrigada é pouco diante de tudo o que vocês fizeram por mim! Essa conquista é de vocês.

A minha doce irmã e afilhada, que mesmo à distância foi primordial nesta caminhada. Você é muito importante e querida!

Aos meus familiares que me receberam no Rio com os braços abertos, ajudando a tornar a minha estadia aqui cada vez mais prazerosa, com carinho todo especial aos Tios com açúcar, Adinet e Egberto, Liese e Eduardo. E a prima que a vida transformou em irmã, Renata, com sua adorada família Flávio e Felipe.

À Dona Ayr, Seu Mário, Cristina e Conrado por agora sermos uma única família, obrigada pelo apoio e incentivo.

A todos os professores de Geotecnia da UnB, que plantaram em mim a semente da vida acadêmica. Em especial a memória do professor Feitosa, figura ímpar, sempre disposto a ajudar e a ensinar.

Ao grande amigo Sérgio Tibana, mais uma vez incansável no apoio, na colaboração e no carinho, e que ainda me presenteou com o convívio de sua doce família.

Aos amigos de todas as horas, com quem pude contar para dividir as muitas alegrias e os momentos angustiantes, Raquel e João Luíz, Ana Ghislaine e Paul, Andreia e Thadeu, Suzana e Rodrigo, Lenita e Renato, Lúcio Flávio; saibam que vocês ocupam um lugar todo especial em meu coração.

Aos amigos que estão distante, mais nem por isso menos amados ou esquecidos: Alvane, a toda família Cajaty Barbosa Braga, Liliam, Evaldo, Eduardo, Deinha e Maurício, Paulinha, Simone e Héctor, Lúcio Flávio e, Carlos Carillo. 
Aos amigos da Pós Graduação do Departamento de Engenharia Civil pela prazerosa convivência e pelas ajudas preciosas: Ana Cristina, Ciro, Ataliba, Ana Júlia, Suzana Costa, Cleide e Eudes, Leonardo Bello, Patrício, Luciana, e, Mônica. Ainda assim é impossível citar todos aqueles que foram importantes para a realização desta tese.

Ao meu amor, Mário, que participou deste "projeto" desde o início, não me restam dúvidas que você foi a melhor parte desta pesquisa, obrigada pela paciência, pelo apoio, pela dedicação e sobretudo por ter se tornado meu esposo. 


\section{Resumo}

Duarte, Anna Paula Lougon; de Campos, Tácio Mauro Pereira; Araruna, José Tavares. Avaliação de Propriedades Termo-Hidráulicas de Solos Requeridas na Aplicação da Técnica de Dessorção Térmica. Rio de Janeiro, 2004. 290p. Tese de Doutorado - Departamento de Engenharia Civil, Pontifícia Universidade Católica do Rio de Janeiro.

A presente tese apresenta uma abordagem sobre a técnica de dessorção térmica na remediação de áreas contaminadas, esta tecnologia se baseia no aquecimento direto do solo. A propagação de calor num solo é simulada matematicamente pelo fluxo acoplado de calor. Para que esta simulação seja possível é necessário a identificação dos parâmetros relevantes para o problema: condutividade hidráulica em função da umidade volumétrica, condutividade térmica em função da umidade volumétrica, capacidade de aquecimento volumétrico, e, curva característica de sucção. Uma discussão técnica é apresentada sobre estes parâmetros.

Foram estudados dois tipos de solos, uma argilo-arenoso (Campo Experimental da PUC-Rio) e um areno-argiloso (Cidade dos Meninos). É apresentado um estudo físico-químico sobre os efeitos da temperatura nos solos, com ensaios de RaiosX, Microscopia Eletrônica, CTC, Ataque Sulfúrico e de Caracterização para solos não aquecidos e previamente aquecidos até a temperatura de $300^{\circ} \mathrm{C}$.

São apresentadas metodologias e equipamentos que foram desenvolvidos e/ou adaptados de para o estudo das propriedades termo-hidráulicas necessárias. Foram realizados ensaios de condutividade hidráulica, curvas características de sucção e deformabilidade, levando-se em conta a temperatura. Todos os parâmetros mostraram-se altamente dependente desta. Os parâmetros térmicos, condutividade térmica e calor específico, foram determinados para estes dois de solos.

\section{Palavras-chave}

Geotecnia ambiental; dessorção térmica; fluxo acoplado de calor e umidade em solos; efeitos de temperatura em solos; ensaios de laboratório; solos nãosaturados. 


\section{Abstract}

Duarte, Anna Paula Lougon; de Campos, Tácio Mauro Pereira; Araruna, José Tavares. A Study of Soil Termo-Hydraulics Properties Required at the Application of the Thermal Desorption. Rio de Janeiro, 2004. 290p. DSc. Thesis -Civil Eng. Dept., Pontifícia Universidade Católica do Rio de Janeiro.

This thesis presents an introduction on the use of the thermal desorption technique that is based on the direct heating of the soil, for the remediation of contaminated areas. Heat propagation through soils can be mathematically simulated using coupled heat-moisture transfer theories. In order to make this simulation possible it is necessary to identify the required parameters: hydraulic conductivity as a function of volumetric water content, thermal conductivity as a function of volumetric water content, volumetric heat capacity, and soil-water characteristic curve. One technical description of such parameters is presented.

Two different kinds of soils were used, one clay-sand $(\mathrm{CH})$ and one sandclay (SC). A study physico-chemical was done talking into consideration the temperature effect on the soils with X-Ray, electron microscopic investigation, CTC, Atterberg Limits and at the particle size distribution. The study was done on pre-heated soils with temperatures ranging from $20^{\circ} \mathrm{C}$ to $300^{\circ} \mathrm{C}$.

Equipments and methodologies have been especially developed for the study of the thermo-hydraulics proprieties. The laboratory tests program consisted of hydraulic conductivity, retention curves and deformability, taking into account the temperature effects. During the tests it was observed that all parameters were temperature dependent. The thermal parameters, thermal conductivity and heat capacity were studied for both soils.

\section{Keywords}

Environmental geotechnical; thermal desorption; coupled heat-moisture transfer; effects of the temperature on soils; laboratory tests; unsaturated soils. 


\section{Sumário}

1 Introdução 34

1.1 Estrutura da Tese 36

2 Dessorção Térmica 38

2.1. Contaminantes 50

3 Modelagem Matemática do Aquecimento de um Solo 53

3.1. Condutividade térmica e capacidade de aquecimento volumétrico 54

3.2. Fenômenos de Transferência de Calor 61

3.3. Fluxos Acoplados 64

4 Efeitos da variação de temperatura nas propriedades dos solos $\quad 74$

4.1. Efeitos da Temperatura no Comportamento Hidráulico 77

4.2. Propriedades da água nos solos e a influência da temperatura 82

5 Características dos Solos e dos Corpos de Prova Utilizados 84

5.1. Solos Utilizados 84

5.1.1. Localização, Clima e Geologia 84

5.1.1.1. Solo Coluvionar - Campo Experimental 84

5.1.1.2. Solo Sedimentar Arenoso - Cidade dos Meninos 86

5.1.2. Caracterização Física dos Materiais 88

5.1.3. Análises Mineralógicas e Geoquímica 94

5.2. Preparação e Confecção das amostras 99

5.2.1. Confecção das amostras - Compactação 99

6 Equipamentos e Metodologias de Ensaios 105

6.1. Condutividade Hidráulica Saturada 107

6.1.1. Metodologia de Ensaio 109

6.2. Condutividade Térmica e Calor Específico 110

$\begin{array}{ll}\text { 6.2.1. Metodologia de Ensaio } & 120\end{array}$ 
6.1.1.1. Condutividade Térmica 120

$\begin{array}{ll}\text { 6.2.1.2. Calor Específico } & 121\end{array}$

6.3. Curvas Características de Sucção 121

6.3.1. Metodologia de Ensaio 123

6.4. Condutividade Hidráulica Saturada com Temperatura Controlada 125

6.4.1. Metodologia de Ensaio 131

6.5. Célula de Compressão Isotrópica com Temperatura Controlada 132

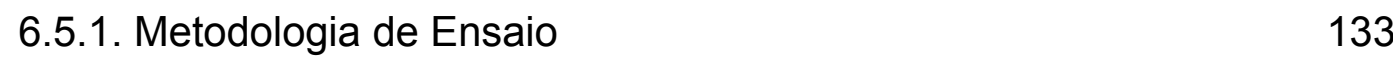

7 Apresentação e Análise dos Resultados 135

7.1. Condutividade Hidráulica Saturada 135

7.2. Condutividade Térmica e Calor Específico 144

$\begin{array}{ll}\text { 7.2.1. Condutividade Térmica } & 144\end{array}$

7.2.2. Calor Específico 155

7.3. Curvas Características de Sucção 162

7.3.1. Curvas de Condutividade Hidráulica Não Saturada 175

7.4. Ensaios de Condutividade Hidráulica Saturada com Temperatura $\begin{array}{ll}\text { Controlada } & 179\end{array}$

7.5. Célula de Compressão Isotrópica com Temperatura Controlada 190

8 Conclusões e Sugestões 198

$\begin{array}{ll}8.1 \text { Conclusões } & 198\end{array}$

8.1.1 Propriedades Físicas, Físico-Químicas e Mineralógicas 199

8.1.2 Condutividade Hidráulica Saturada 200

8.1.3 Condutividade Térmica e Calor Específico 202

8.1.4 Curvas Características de Sucção 204

8.1.5 Aplicação da Técnica de Dessorção Térmica 205

$\begin{array}{ll}8.2 \text { Sugestões para pesquisas futuras } & 206\end{array}$

9 REFERÊNCIAS BIBLIOGRAFICAS 208

Apêndice A - Calibração da Instrumentação 218

A.1 Calibrações para Permeâmetro de Parede Flexível e Carga Constante 
A.1.1. Transdutores de Pressão 219

A.1.2. Medidor de Variação Volumétrica 220

A.2. Calibrações para Permeâmetro de Temperatura Controlada 220

A.2.1. Transdutores de Pressão 220

A.2.2. Medidor de Variação Volumétrica 223

A.2.3. Calibração dos Termopares 223

Apêndice B Gráficos dos Ensaios de Permeabilidade Saturada 228

B.1. Ensaios com o Permeâmetro de Parede Flexível e Carga Constante

B.1.1. Solo do Campo Experimental 229

B.1.2. Solo da Cidade dos Meninos 236

B.2. Ensaios de Permeabilidade Saturada com Temperatura Controlada

B.2.1. Solo do Campo Experimental

B.2.2. Solo da Cidade dos Meninos

Apêndice C Dados para a obtenção do Calor Específico 255

C.1. Solo do Campo Experimental 256

C.2. Solo da Cidade dos Meninos 259

Apêndice D Dados para a Obtenção da Curva Característica 262

D.1. Solo do Campo Experimental 263

D.1.1. Curva do Material Seco ao Ar 263

D.1.2. Curva do Material Natural 263

D.1.3. Curva do Material Saturado 264

D.1.4. Curva do Material Submetido a Temperatura de $50^{\circ} \mathrm{C} \quad 265$

D.1.5. Curva do Material Submetido a Temperatura de $100^{\circ} \mathrm{C} \quad 265$

D.1.6. Curva Característica do Material Submetido a $200^{\circ} \mathrm{C} .272$

D.1.7. Curva Característica do Material Submetido a $300^{\circ} \mathrm{C}$. 273

D.1.8. Curva Característica do Material Submetido a $100^{\circ} \mathrm{C}$ e Saturado. 
D.1.9. Curva Característica do Material Submetido a $300^{\circ} \mathrm{C}$ e Saturado.

274

D.2. Solo da Cidade dos Meninos 275

D.2.1. Curva do Material Natural 275

D.2.2. Curva do Material Submetido a $100^{\circ} \mathrm{C}$

D.2.3. Curva do Material Submetido a $200^{\circ} \mathrm{C} \quad 276$

D.2.4. Curva do Material Submetido a $300^{\circ} \mathrm{C}$

Apêndice E Dados de Variação de Volume com a Temperatura $\quad 278$

E.1. Solo do Campo Experimental 279

E.2. Solo da Cidade dos Meninos 285 


\section{Lista de Figuras}

Figura 1 - Sistemas de Dessorção Térmica in situ (Terratherm, 2001). 42

Figura 2- Relação entre temperatura e pressão de vapor (EPA, 1998) 45

Figura 3- Variação da viscosidade e peso específico da água com a temperatura.

Figura 4 - Localização do Campo Experimental II da PUC-Rio. (Beneveli, 2002) 85

Figura 5 - Descrição morfológica do perfil (Daylac, 1994) 86

Figura 6 - Mapa da cidade do Rio de Janeiro destacando a Cidade dos Meninos

Figura 7 - Localização da retirada das amostras e direção do fluxo d'água subterrânea.

Figura 8 - Curvas granulométricas 89

Figura 9 - Curvas granulométricas dos solos pré-aquecidos: (a) solo do Campo Experimental, (b) solo da Cidade dos Meninos.

Figura 10 - Variações dos Limites de Atterberg: (a) solo do Campo Experimental, (b) solo da Cidade dos Meninos

Figura 11 - Difratogramas de Raios-X do solo do Campo Experimental. 97 Figura 12 - Difratogramas de Raio-X do solo da Cidade dos Meninos. 97 Figura 13 - Mudança na coloração das amostras com a temperatura:

Campo Experimental (a), Cidade dos Meninos (b) 98

Figura 14 - Esquema do molde de compactação 100

Figura 15 - Foto do Molde 100

Figura 16 -Fotografias da Prensa de adensamento Modelo Bishop utilizadas: (a) vista frontal e (b) vista lateral.

Figura 17 - Variação dos pesos específicos segundo pressão de compactação.

Figura 18 - Curvas de Compactação Estática para pressão de 500kPa:

(a) solo do Campo Experimental e (b) solo da Cidade dos Meninos. 
Figura 19 - Permeâmetro desenvolvido no laboratório de Geotecnia da PUC-Rio

Figura 20 - Representação esquemática do permeâmetro 108

Figura 21 - Esquema de sonda térmica 114

Figura 22- Sonda térmica e Data-Logger 116

Figura 23 - Molde de latão e placas isolantes para a medição do calor específico. 117

Figura 24 - Medição do calor específico 117

Figura 25 - Termômetro digital MINIPA 118

Figura 26 - Curva de fator tempo para fluxo de calor radial. Michell e Kao

Figura 27 - Detalhe da câmara de aço 125

Figura 28 - Unidade de controle de temperatura 126

Figura 29 - Detalhes do sistema de aquecimento 127

Figura 30 - Detalhe do medidor de variação de volume e do LSCDT 128

Figura 31 - Detalhe dos termopares instalados na base e no topo da amostra 129

Figura 32 - Permeâmetro de temperatura controlada 129

Figura 33 - Diagrama esquemático do permeâmetro de temperatura controlada.

Figura 34 - Medidor de variação volumétrica com temperatura controlada.

Figura 35 - Ensaio de condutividade hidráulica da amostra a temperatura ambiente para o solo do Campo Experimental: (a) variação de volume com o tempo; (b) variação do gradiente hidráulico com o tempo;

(c)variação da condutividade hidráulica com o tempo.

Figura 36 - Variação da condutividade hidráulica para corpos de prova submetidos a gradientes de temperatura em mufla e ensaiados a temperatura ambiente.

Figura 37 - Imagens das lâminas com microscópio eletrônico

Figura 38 - Variação do fator de forma C para corpos de prova 
submetidos a diferentes gradientes de temperatura em mufla.

Figura 39 - Variação do índice de vazios com a umidade, limite de contração:

(a) solo do Campo Experimental, (b) solo da Cidade dos Meninos.

Figura 40 - Curva de condutividade térmica x umidade gravimétrica (a);

condutividade térmica $x$ grau de saturação(b); condutividade térmica $x$

umidade volumétrica (c).

Figura 41- Comparação dos valores de condutividade térmica

Figura 42 - Previsões da condutividade térmica com a umidade gravimétrica

Figura 43 - Previsões da condutividade térmica com o grau de saturação

Figura 44- Variação da temperatura com o tempo para o solo do Campo

Experimental com umidade higroscópica de 1,42\%

Figura 45- Relação do calor específico com a temperatura para o solo do

Campo Experimental.

Figura 46- Relação do calor específico com a temperatura para o solo da Cidade dos Meninos.

Figura 47 - Variação do calor específico com a temperatura analisando-se o índice de vazios.

Figura 48 - Curva característica em função do teor de umidade em peso.

Figura 49- Curva característica em função do teor de umidade volumétrica

Figura 50- Curva característica em função do grau de saturação.

Figura 51 -Curvas características em função do teor de umidade em peso para diferentes temperaturas: (a) solo do Campo Experimental, (b) solo da Cidade dos Meninos.

Figura 52- Curva característica em função do teor de umidade volumétrica para corpos de prova submetidos a diferentes gradientes de temperaturas: (a) solo do Campo Experimental, (b) solo da Cidade dos Meninos.

Figura 53 -Curvas características da Campo Experimental em função do 
teor de umidade em peso para diferentes temperaturas seguindo-se a trajetória de secagem.

Figura 54 -Curvas obtidas para o solo do Campo Experimental: (a) Curva Característica, (b) Condutividade hidráulica não saturada.

Figura 55 -Curvas obtidas para o solo da Cidade dos Meninos: (a) Curva

Característica, (b) Condutividade hidráulica não saturada.

Figura 56 - Ensaio de condutividade hidráulica da amostra do Campo Experimental à $40^{\circ} \mathrm{C}$ : (a) variação de volume com o tempo; (b) variação do gradiente hidráulico com o tempo; (c)variação da condutividade hidráulica com o tempo; (d) variação da temperatura com o tempo. 180 Figura 57 - Variação da condutividade hidráulica com a temperatura. 181 Figura 58- Variação da condutividade hidráulica intrínseca com a temperatura.

Figura 59 - Variação dos Parâmetros com a temperatura para o solo do Campo Experimental: (a) variação de volume x temperatura, (b) variação do índice de vazios $\mathrm{x}$ temperatura, (c) $\Delta \mathrm{V} \mathrm{N}_{\mathrm{m}} \mathrm{x}$ temperatura, (d) $\alpha_{\mathrm{T}} \mathrm{X}$ temperatura.

Figura 60 - Variação dos Parâmetros com a temperatura para o solo da Cidade dos Meninos: (a) variação de volume $x$ temperatura, (b) variação do índice de vazios $\mathrm{x}$ temperatura, (c) $\Delta \mathrm{V} / \mathrm{N}_{\mathrm{m}} \mathrm{x}$ temperatura, (d) $\alpha_{\mathrm{T}} \mathrm{X}$ temperatura.

Figura 61 - Variação da condutividades hidráulicas com a temperatura189 Figura 62 - Ensaio para o solo do Campo Experimental na temperatura de $32^{\circ} \mathrm{C}$ : (a) variação da poropressão com o tempo; (b) variação de volume com o tempo.

Figura 63 - Ensaio de variação de volume para o solo da Cidade dos Meninos na temperatura de $32,30^{\circ} \mathrm{C}$ : (a) variação da poropressão com o tempo; (b) variação de volume com o tempo.

Figura 64 - Variação dos Parâmetros com a temperatura para o solo do Campo Experimental: (a) variação de volume x temperatura, (b) variação do índice de vazios $x$ temperatura, (c) $\Delta \mathrm{V} \mathrm{N}_{\mathrm{m}} \mathrm{x}$ temperatura, (d) $\alpha \mathrm{t} \mathrm{x}$ temperatura.

Figura 65 - Variação dos Parâmetros com a temperatura para o solo da 
Cidade dos Meninos: (a) variação de volume $\mathrm{x}$ temperatura, (b) variação do índice de vazios $x$ temperatura, (c) $\Delta V / N_{m} x$ temperatura, (d) $\alpha$ t $x$ temperatura.

Figura 66 - Comparação da variação da condutividade hidráulica medida e estimada com a temperatura: (a) solo do Campo Experimental, (b) solo da Cidade dos Meninos.

Figura 67 - Calibração do transdutor de poropressão - n00958 219

Figura 68 - Calibração do transdutor de poropressão - n02858 219

Figura 69 - Calibração do medidor de variação volumétrica 220

Figura 70- Calibração do transdutor de poropressão(n05290393) em função da temperatura

Figura 71- Calibração do transdutor de poropressão(n05290391) em função da temperatura

Figura 72 - Calibração do medidor de variação volumétrica.

Figura 73 - Calibração dos termopares com o auxílio do banho-maria 224

Figura 74 - Estabilização das temperaturas no termopar 1

Figura 75 - Estabilização das temperaturas no termopar 2226

Figura 76- Equações de calibração dos termopares 227

Figura 77 - Ensaio de permeabilidade da amostra a temperatura ambiente: (a) variação do volume com o tempo; (b) variação do gradiente hidráulico com o tempo; (c) variação da condutividade hidráulica com o tempo

Figura 78 - Ensaio de permeabilidade da amostra submetida a um gradiente de $50^{\circ} \mathrm{C}$ : (a)variação do volume com o tempo; (b) variação do gradiente hidráulico com o tempo; (c) variação da condutividade hidráulica com o tempo.

Figura 79 - Ensaio de permeabilidade da amostra submetida a um gradiente de $100^{\circ} \mathrm{C}$ : (a)variação do volume com o tempo; (b) variação do gradiente hidráulico com o tempo; (c) variação da condutividade hidráulica com o tempo 231

Figura 80 - Ensaio de permeabilidade da amostra submetida a um 
gradiente de $150^{\circ} \mathrm{C}$ : (a)variação do volume com o tempo; (b) variação do gradiente hidráulico com o tempo; (c) variação da condutividade hidráulica com o tempo.

Figura 81 - Ensaio de permeabilidade da amostra submetida a um gradiente de $200^{\circ} \mathrm{C}$ : (a)variação do volume com o tempo; (b) variação do gradiente hidráulico com o tempo; (c) variação da condutividade hidráulica com o tempo.

Figura 82 - Ensaio de permeabilidade da amostra submetida a um gradiente de $250^{\circ} \mathrm{C}$ : (a)variação do volume com o tempo; (b) variação do gradiente hidráulico com o tempo; (c) variação da condutividade hidráulica com o tempo

Figura 83 - Ensaio de permeabilidade da amostra submetida a um gradiente de $300^{\circ} \mathrm{C}$ : (a)variação do volume com o tempo; (b) variação do gradiente hidráulico com o tempo; (c) variação da condutividade hidráulica com o tempo .

Figura 84 - Ensaio de permeabilidade da amostra a temperatura ambiente: (a)variação do volume com o tempo; (b) variação do gradiente hidráulico com o tempo; (c) variação da condutividade hidráulica com o tempo.

Figura 85 - Ensaio de permeabilidade da amostra submetida a um gradiente de $100^{\circ} \mathrm{C}$ : (a)variação do volume com o tempo; (b) variação do gradiente hidráulico com o tempo; (c) variação da condutividade hidráulica com o tempo.

Figura 86 - Ensaio de permeabilidade da amostra submetida a um gradiente de $200^{\circ} \mathrm{C}$ : (a)variação do volume com o tempo; (b) variação do gradiente hidráulico com o tempo; (c) variação da condutividade hidráulica com o tempo. 238

Figura 87 - Ensaio de permeabilidade da amostra submetida a um gradiente de $300^{\circ} \mathrm{C}$ : (a)variação do volume com o tempo; (b) variação do gradiente hidráulico com o tempo; (c) variação da condutividade hidráulica com o tempo.

Figura 88 - Ensaio de permeabilidade da amostra a temperatura ambiente: (a)variação do volume com o tempo; (b) variação do gradiente 
hidráulico com o tempo; (c) variação da condutividade hidráulica com o tempo; (d) variação da temperatura com o tempo.

Figura 89 - Ensaio de permeabilidade com a amostra na temperatura de $30,5^{\circ} \mathrm{C}$ : (a)variação do volume com o tempo; (b) variação do gradiente hidráulico com o tempo; (c) variação da condutividade hidráulica com o tempo; (d) variação da temperatura com o tempo.

Figura 90 - Ensaio de permeabilidade com a amostra na temperatura de 40,4 C: (a)variação do volume com o tempo; (b) variação do gradiente hidráulico com o tempo; (c) variação da condutividade hidráulica com o tempo; (d) variação da temperatura com o tempo.

Figura 91 - Ensaio de permeabilidade com a amostra na temperatura de $50,6^{\circ} \mathrm{C}$ : (a)variação do volume com o tempo; (b) variação do gradiente hidráulico com o tempo; (c) variação da condutividade hidráulica com o tempo; (d) variação da temperatura com o tempo.

Figura 92 - Ensaio de permeabilidade com a amostra na temperatura de $60,2^{\circ} \mathrm{C}$ : (a)variação do volume com o tempo; (b) variação do gradiente hidráulico com o tempo; (c) variação da condutividade hidráulica com o tempo; (d) variação da temperatura com o tempo.

Figura 93 - Ensaio de permeabilidade com a amostra na temperatura de $68,8^{\circ} \mathrm{C}$ : (a)variação do volume com o tempo; (b) variação do gradiente hidráulico com o tempo; (c) variação da condutividade hidráulica com o tempo; (d) variação da temperatura com o tempo.

Figura 94 - Ensaio de permeabilidade com a amostra na temperatura de $77,5^{\circ} \mathrm{C}$ : (a)variação do volume com o tempo; (b) variação do gradiente hidráulico com o tempo; (c) variação da condutividade hidráulica com o tempo; (d) variação da temperatura com o tempo.

Figura 95 - Ensaio de permeabilidade da amostra a temperatura ambiente: (a)variação do volume com o tempo; (b) variação do gradiente hidráulico com o tempo; (c) variação da condutividade hidráulica com o tempo; (d) variação da temperatura com o tempo.

Figura 96 - Ensaio de permeabilidade com a amostra na temperatura de $30,8^{\circ} \mathrm{C}$ : (a)variação do volume com o tempo; (b) variação do gradiente hidráulico com o tempo; (c) variação da condutividade hidráulica com o 
tempo; (d) variação da temperatura com o tempo.

Figura 97 - Ensaio de permeabilidade com a amostra na temperatura de $41,0^{\circ} \mathrm{C}$ : (a)variação do volume com o tempo; (b) variação do gradiente hidráulico com o tempo; (c) variação da condutividade hidráulica com o tempo; (d) variação da temperatura com o tempo.

Figura 98 - Ensaio de permeabilidade com a amostra na temperatura de $51,4^{\circ} \mathrm{C}$ : (a)variação do volume com o tempo; (b) variação do gradiente hidráulico com o tempo; (c) variação da condutividade hidráulica com o tempo; (d) variação da temperatura com o tempo.

Figura 99 - Ensaio de permeabilidade com a amostra na temperatura de $60,3^{\circ} \mathrm{C}$ : (a)variação do volume com o tempo; (b) variação do gradiente hidráulico com o tempo; (c) variação da condutividade hidráulica com o tempo; (d) variação da temperatura com o tempo.

Figura 100 - Ensaio de permeabilidade com a amostra na temperatura de $69,8^{\circ} \mathrm{C}$ : (a)variação do volume com o tempo; (b) variação do gradiente hidráulico com o tempo; (c) variação da condutividade hidráulica com o tempo; (d) variação da temperatura com o tempo.

Figura 101 - Ensaio de permeabilidade com a amostra na temperatura de $77,5^{\circ} \mathrm{C}$ : (a)variação do volume com o tempo; (b) variação do gradiente hidráulico com o tempo; (c) variação da condutividade hidráulica com o tempo; (d) variação da temperatura com o tempo.

Figura 102- Ensaio de calor específico para o solo do Campo Experimental, CP 1.

Figura 103- Ensaio de calor específico para o solo do Campo Experimental, CP 2.

Figura 104- Ensaio de calor específico para o solo do Campo Experimental, CP 3.

Figura 105- Ensaio de calor específico para o solo do Campo Experimental, CP 4.

Figura 106- Ensaio de calor específico para novas condições de compactação, e=1,324.

Figura 107- Ensaio de calor específico para novas condições de 
compactação, e=1,253.

Figura 108- Ensaio de calor específico para o solo da Cidade dos Meninos, CP 1.

Figura 109- Ensaio de calor específico para o solo da Cidade dos Meninos, CP 2.

Figura 110- Ensaio de calor específico para o solo da Cidade dos Meninos, CP 3.

Figura 111- Ensaio de calor específico para o solo da Cidade dos Meninos, CP 4.

Figura 112- Ensaio de calor específico para novas condições de compactação, e=0,75.

Figura 113- Ensaio de calor específico para novas condições de compactação, e=0,84.

Figura 114- Determinação do peso no tempo zero - CP1 (a)após o contato com o solo, (b) após secagem em estufa. Temperatura de $100^{\circ} \mathrm{C} . \quad 265$ Figura 115- Determinação do peso no tempo zero - CP2: (a) após o comtato com o solo, (b) após secagem em estufa. Temperatura de $100^{\circ} \mathrm{C} .266$ Figura 116- Determinação do peso no tempo zero - CP3: (a) após o comtato com o solo, (b) após secagem em estufa. Temperatura de $100^{\circ} \mathrm{C} .267$ Figura 117- Determinação do peso no tempo zero - CP4: (a) após o comtato com o solo, (b) após secagem em estufa. Temperatura de $100^{\circ} \mathrm{C} .267$ Figura 118- Determinação do peso no tempo zero - CP5: (a) após o comtato com o solo, (b) após secagem em estufa. Temperatura de $100^{\circ} \mathrm{C} .267$ Figura 119- Determinação do peso no tempo zero - CP6 (a) após o comtato com o solo, (b) após secagem em estufa. Temperatura de $100^{\circ} \mathrm{C} .268$ Figura 120- Determinação do peso no tempo zero - CP7: (a) após o comtato com o solo, (b) após secagem em estufa. Temperatura de $100^{\circ} \mathrm{C} .268$ Figura 121- Determinação do peso no tempo zero - CP8 (a) após o comtato com o solo, (b) após secagem em estufa. Temperatura de $100^{\circ} \mathrm{C} .268$ Figura 122- Determinação do peso no tempo zero - CP9 (a)após o comtato com o solo, (b) após secagem em estufa. Temperatura de $100^{\circ} \mathrm{C} .269$ Figura 123- Determinação do peso no tempo zero - CP10 (a)após o comtato com o solo, (b) após secagem em estufa. Temperatura de $100^{\circ} \mathrm{C} .269$ 
Figura 124- Determinação do peso no tempo zero - CP11: (a) após o com-tato com o solo, (b) após secagem em estufa. Temperatura de $100^{\circ} \mathrm{C}$.

Figura 125- Determinação do peso no tempo zero - CP12 (a) após o comtato com o solo, (b) após secagem em estufa. Temperatura de $100^{\circ} \mathrm{C}$. 270 Figura 126- Determinação do peso no tempo zero - CP13 (a)após o comtato com o solo, (b) após secagem em estufa. Temperatura de $100^{\circ} \mathrm{C} .270$ Figura 127- Determinação do peso no tempo zero - CP14 (a)após o comtato com o solo, (b) após secagem em estufa. Temperatura de $100^{\circ} \mathrm{C} .270$ Figura 128- Determinação do peso no tempo zero - CP15: (a) após o com-tato com o solo, (b) após secagem em estufa. Temperatura de $100^{\circ} \mathrm{C}$.

Figura 129- Determinação do peso no tempo zero - CP16 (a) após o comtato com o solo, (b) após secagem em estufa. Temperatura de $100^{\circ} \mathrm{C} .271$ Figura 130- Determinação do peso no tempo zero - CP17 (a)após o comtato com o solo, (b) após secagem em estufa. Temperatura de $100^{\circ} \mathrm{C} .271$ Figura 131- Determinação do peso no tempo zero - CP18 (a)após o comtato com o solo, (b) após secagem em estufa. Temperatura de $100^{\circ} \mathrm{C} .272$

Figura 132- Ensaio de variação de volume para o solo do Campo Experimental, estágio de $30^{\circ} \mathrm{C}$.

Figura 133- Ensaio de variação de volume para o solo do Campo Experimental, estágio de $40^{\circ} \mathrm{C}$.

Figura 134- Ensaio de variação de volume para o solo do Campo Experimental, estágio de $50^{\circ} \mathrm{C}$.

Figura 135- Ensaio de variação de volume para o solo do Campo Experimental, estágio de $60^{\circ} \mathrm{C}$.

Figura 136- Ensaio de variação de volume para o solo do Campo Experimental, estágio de $70^{\circ} \mathrm{C}$.

Figura 137- Ensaio de variação de volume para o solo do Campo Experimental, estágio de $80^{\circ} \mathrm{C}$.

Figura 138- Ensaio de variação de volume para o solo da Cidade dos Meninos, estágio de $30^{\circ} \mathrm{C}$. 
Figura 139- Ensaio de variação de volume para o solo da Cidade dos Meninos, estágio de $40^{\circ} \mathrm{C}$.

Figura 140- Ensaio de variação de volume para o solo da Cidade dos Meninos, estágio de $50^{\circ} \mathrm{C}$.

Figura 141- Ensaio de variação de volume para o solo da Cidade dos Meninos, estágio de $60^{\circ} \mathrm{C}$.

Figura 142- Ensaio de variação de volume para o solo da Cidade dos Meninos, estágio de $70^{\circ} \mathrm{C}$.

Figura 143- Ensaio de variação de volume para o solo da Cidade dos Meninos, estágio de $80^{\circ} \mathrm{C}$. 


\section{Lista de tabelas}

Tabela 1 - Técnicas para Controle e Remediação de Áreas

Contaminadas(Evans, 1991). 39

Tabela 2- Custo para técnicas de remediações. (Wood, 1997). 41

Tabela 3 - Propriedades de alguns químicos orgânicos que tem sido encontrados em áreas contaminadas. 52

Tabela 4 - Analogias de Fluxo (Mitchell, 1993). 54

Tabela 5 - Propriedades Térmicas do Solo (modificado Mitchell, 1993) 56

Tabela 6 - Fenômenos de fluxo acoplado e fluxo direto (Mitchell, 1975). 64

Tabela 7 - Propriedades físicas da água em estado líquido 83

Tabela 8 - Caracterização geotécnica dos solos

Tabela 9-Índices físicos obtidos para a encosta do Campo Experimental90

Tabela 10- Índices Físicos obtidos para amostras da Cidade dos Meninos

Tabela 11 - Cátions Trocáveis e Análise Química- Campo Experimental

Tabela 12- Cátions Trocáveis e Análise Química- Cidade dos Meninos 95 Tabela 13 - Variações de peso específico e umidade com a pressão de compactaçã

Tabela 15 - Dados após compactação dos corpos de prova - Campo

Experimental

Tabela 16 - Dados após compactação dos corpos de prova - Cidade dos Meninos

Tabela 17 - Dados iniciais dos Corpos de Prova ensaiados - Campo 
Tabela 18 - Dados iniciais de cada corpo de prova - Cidade dos Meninos

Tabela 19 - Dados Inicias dos Corpos de Prova

Tabela 20 - Dados dos corpos de prova e resultados de condutividade térmica - Campo Experimental

Tabela 21 - Dados dos corpos de prova e resultados de condutividade térmica - Cidade dos Meninos

Tabela 22 - Dados Inicias dos Corpos de Prova

Tabela 23 - Dados dos corpos de prova utilizados na determinação do calor específico

Tabela 24- Valores de calor específico com relação a umidade e temperatura para o solo do Campo Experimental.

Tabela 25- Valores de calor específico com relação a umidade e temperatura para o solo da Cidade dos Meninos.

Tabela 26- Parâmetros das curvas características para o solo do Campo

Experimental

Tabela 27- Parâmetros das curvas características para o solo da Cidade dos Meninos

Tabela 28- Parâmetros das curvas características x umidade volumétrica para o solo do Campo Experimental.

Tabela 29- Parâmetros das curvas características $x$ umidade volumétrica para o solo da Cidade dos Meninos.

Tabela 30- Parâmetros das curvas características seguindo-se a trajetória de secagem para o solo do Campo Experimental.

Tabela 31- Parâmetros das equações de Van Genuchten.

Tabela 32 - Dados de cada corpo de prova ensaiados do solo do Campo Experimental

Tabela 33 - Dados de cada corpo de prova ensaiados do solo da Cidade dos Meninos.

Tabela 34 - Dados finais do ensaio do solo do Campo Experimental 187

Tabela 35 - Dados finais do ensaio do solo da Cidade dos Meninos 187

Tabela 36 - Comparação das condutividades hidráulicas obtidas 188

Tabela 37 - Dados dos corpos de prova ensaiados. 
Tabela 38 - Resultados do ensaio de dissipação.

Tabela 39- Características dos elementos elétricos utilizados

Tabela 40- Dados iniciais dos corpos de prova do material natural seco ao ar.

Tabela 41- Parâmetros do solo ensaiado do material natural seco ao ar

Tabela 42 - Dados iniciais dos corpos de prova do material natural

Tabela 43 - Parâmetros do solo ensaiado da curva característica do material natural

Tabela 44 - Dados Iniciais dos Corpos de prova do material natural saturado

Tabela 45 - Parâmetros do solo ensaiado da curva característica do material natural saturado

Tabela 46 - Dados Iniciais dos corpos de prova após compactação 265 Tabela 47 - Parâmetros do solo ensaiado do Material aquecido a 50oC.

Tabela 48 - Dados Iniciais dos corpos de prova após compactação. 266 Tabela 49 - Parâmetros do solo ensaiado do Material aquecido a 100oC

Tabela 50 - Dados iniciais dos corpos de prova do material após a compactação.

Tabela 51 - Parâmetros do solo ensaiado da curva característica do material submetido a $2000 \mathrm{C}$.

Tabela 52 - Dados Iniciais dos Corpos de prova do material após a compactação.

Tabela 53 - Parâmetros do solo ensaiado da curva característica do material submetido a $3000 \mathrm{C}$.

Tabela 54 - Dados Iniciais dos corpos de prova do material após a compactação.

Tabela 55 - Parâmetros do solo ensaiado da curva característica do material submetido a $1000 \mathrm{C}$ e depois saturado. 
Tabela 56 - Dados Iniciais dos Corpos de prova do material após a compactação 274

Tabela 57 - Parâmetros do solo ensaiado da curva característica do material submetido a $300 \mathrm{oC}$ e posteriormente saturado.

274

Tabela 58 - Dados iniciais dos corpos de prova após a compactação. 275

Tabela 59 - Parâmetros do solo ensaiado da curva característica do material natural 275

Tabela 60 - Dados iniciais dos corpos de prova do material após a compactação.

Tabela 61 - Parâmetros do solo ensaiado da curva característica do material submetido a $100 \mathrm{oC}$.

Tabela 62 - Dados Iniciais dos corpos de prova do material após a compactação.

Tabela 63 - Parâmetros do solo ensaiado da curva característica do material submetido a 200 oC.

Tabela 64 - Dados Iniciais dos corpos de prova do material após a compactação.

Tabela 65 - Parâmetros do solo ensaiado da curva característica do material submetido a $300 \mathrm{oC}$.

Tabela 66- Parâmetros iniciais do solo ensaiado 279

Tabela 67- Parâmetros iniciais do solo ensaiado Cidade dos Meninos 285 


\section{Lista de Símbolos}

a - umidade volumétrica do ar

Ativ. - atividade

$\alpha$ - fator de tortuosidade para difusão de gases em solos

$\alpha_{S}$ - coeficiente térmico da expansão cúbica do mineral sólido.

$\alpha_{\mathrm{ST}}$ - coeficiente físico-químico estrutural da variação de volume devido a temperatura

$\alpha_{\mathrm{w}}$ - coeficiente térmico de expansão da água do solo

$\beta$ - fator de conversão de unidades

$\mathrm{C}$ - fator de forma

c - calor específico

$\mathrm{C}_{\mathrm{a}}$ - calor específico do ar

$\mathrm{c}_{\mathrm{n}}$ - calor específico do solo

$\mathrm{C}_{\mathrm{s}}$ - calor especifico dos sólidos

$\mathrm{C}_{\mathrm{w}}$ - calor específico da água na fase líquida

$\mathrm{C}(\theta)$ - capacidade de aquecimento volumétrica do meio poroso

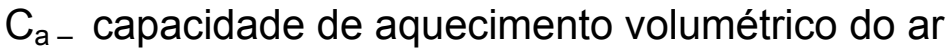

$\mathrm{C}_{\mathrm{M}}$ - capacidade de aquecimento volumétrico do meio seco

$\mathrm{C}_{\mathrm{s}}$ - capacidade de aquecimento volumétrico dos sólidos

$\mathrm{C}_{\mathrm{w}}$ - capacidade de aquecimento volumétrica da fase líquida

d- diâmetro do cilindro

D - difusividade térmica

$\mathrm{D}_{0}$ - difusividade molecular do vapor d'água no ar

$D_{S}$ - diâmetro médio dos grãos

$\mathrm{D}_{\mathrm{T}}$ - difusividade térmica da água

$\mathrm{D}_{\mathrm{Ta}}$ - coeficiente relacionando com o aquecimento da água adsorvida

$D_{T L}-$ difusividade térmica do líquido

$D_{T V}$ - difusividade térmica do vapor

$\mathrm{D}_{\theta}$ - difusividade isotérmica da água

$D_{\theta L}$ - difusividade isotérmica do líquido 
$D_{\theta V}$ - difusividade isotérmica do vapor

$\delta$ - delta de Kronecker.

$\Delta \mathrm{T}$ - variação de temperatura

e - índice de vazios

$\bar{e}$ - índice de vazios efetivos

$e_{o}$ água adsorvida no índice de vazios

$\varepsilon_{V T}$ - deformação volumétrica devido a variação de temperatura

$\phi$ - diâmetro do corpo de prova

g - gravidade

$\gamma$ - peso específico

$\gamma_{d}-$ peso específico seco

$\gamma_{w}$ - peso específico da água

$\mathrm{h}$ - umidade relativa do ar nos poros

i - vetor unitário na direção vertical

$\mathrm{i}_{\mathrm{h}}$ - gradiente hidráulico

$\mathrm{i}_{\mathrm{t}}$ - gradiente térmico

IP - índice de plasticidade

k - condutividade hidráulica

$\mathrm{k}_{\theta}$ - condutividade hidráulica não saturada

$\mathrm{L}$ - calor latente de vaporização da água

$\mathrm{L}_{0}$ - calor latente de vaporização numa dada temperatura de referência $T_{0}$

$\mathrm{L}_{\mathrm{ij}}$ - coeficiente acoplados

LL - limite de liquidez

LP - limite de plasticidade

$\lambda$ - condutividade térmica

$\lambda_{e}$ - condutividade térmica normalizada

$\lambda_{\mathrm{ij}}$ - condutividade térmica de um meio poroso úmido

$\lambda_{\mathrm{q}}$ - condutividade térmica do quartzo

$\lambda_{\mathrm{s}}$ - condutividade térmica do solo

$\lambda_{\text {sat }}$ - condutividade térmica saturada

$\lambda_{\text {seco }}$ - condutividade térmica seca

$\lambda_{\mathrm{w}}$ - condutividade térmica da água 
$M$ - coeficiente de variação de volume

$\mathrm{n}$ - porosidade

$\mu$ - viscosidade do permeante

$v$ - viscosidade cinemática do fluído

p - pressão parcial do vapor de água nos vazios

$P$ - pressão total de gás nos vazios

$\mathrm{q}_{\mathrm{h}}$ - fluxo de água

qliq $_{\text {- fluxo líquido }}$

$\mathrm{q}_{\mathrm{m}}$ - fluxo de umidade

$q_{t}$ - fluxo de calor

$q_{\text {vap }}$ - fluxo de vapor

$\theta$ - teor de umidade volumétrica

$\theta_{\mathrm{i}}$ - teor de umidade volumétrica do ponto de inflexão

$\theta_{\mathrm{r}}-$ teor de umidade volumétrica residual

$\theta_{\mathrm{s}}-$ teor de umidade volumétrica saturado

$r$ - distância radial da fonte

$\mathrm{R}$ - constante universal dos gases

$\rho_{0}$ - densidade do vapor de água saturado

$\rho_{d}=$ massa específica seca do solo

$\rho_{\mathrm{v}}$ - densidade do vapor d'água

$\rho_{\mathrm{w}}$ - densidade da água

S - grau de saturação

$S_{h}$ - teor térmico do meio poroso

$\mathrm{t}$ - tempo

$t_{50}$ - tempo no qual ocorre $50 \%$ da mudança de temperatura no centro da amostra

T - Temperatura

$\mathrm{T}_{50}$ - fator tempo para $50 \%$ de variação da temperatura

$\sigma$ - tensão superficial da água

$\mathrm{V}$ - volume de fluído

$\mathrm{V}_{\mathrm{m}}$ - volume total a temperatura inicial.

$\mathrm{V}_{\mathrm{s}}$ - volume dos Minerais Sólidos

$V_{v}-$ volume total de vazios 
$\overline{V_{v}}$ - volume efetivo de vazios

$\mathrm{V}_{\mathrm{vo}}$ - volume de água adsorvida

$\mathrm{V}_{\mathrm{w}}$ - volume de água dos vazios

$v$ - fator fluxo massa

$v$ - energia térmica

w - umidade gravimétrica

$\mathrm{w}_{\text {nat }}$ - umidade natural do solo

W - calor de molhamento diferencial

$\mathrm{X}_{\mathrm{j}}$ - força governante

$\Psi$ - carga total de sucção

$\Psi_{\mathrm{i}}$ - sucção correspondente à umidade volumétrica do ponto de inflexão $\left(\theta_{\mathrm{i}}\right)$

$\Psi_{\mathrm{r}}$ - sucção correspondente à umidade volumétrica residual $\left(\theta_{\mathrm{r})}\right.$

$\xi$-razão da variação do gradiente de temperatura nos poros completamente ocupados por ar em relação ao gradiente de temperatura total 
“...Viver e não ter a vergonha de ser feliz E cantar, e cantar, e cantar, a beleza de ser um eterno APRENDIZ Ah meu Deus,

eu sei que a vida poderia ser bem melhor e será Mais isso não impede que eu repita:

é bonita, é bonita e é bonita..." 